\title{
Research on the Salary System Design of the Technical Personnel in State-owned Enterprises - Take Changqing Oilfield Exploration and Development Research Institute as an example
}

\author{
Yongxiang Ma \\ School of Economics and Management, Longdong University, Qingyang, \\ Gansu, 745000, China
}

\begin{abstract}
Salary design is an important system for enterprise to solve the defects of single distribution system, and it is also an important tool to improve employee satisfaction and work enthusiasm, plan enterprise labour cost rationally, realize the basic goal of enterprise survival and the long-term development goal. This paper analyzes the serious problems of the technical personnel in the Exploration and Development Institute of Changqing Oilfield, analyzes the shortcomings of the existing wage system, and puts forward the positional core salary and personal performance as the core performance for the technical personnel of the institute. The paper designs a salary incentive model based on personal performance as the evaluation standard, and designs a compensation management model which has strong incentive intensity, fair internal and competitive outside.

Keywords: salary, incentive, post salary points, performance
\end{abstract}

\section{Introduction}

For a long time, the salary incentive of enterprise science and technology talents has been the focus of theorists and practitioners. Since the reform and opening up, the salary reform of state-owned enterprises has increasingly become the focus of the government to implement wage reform, has become the focus of all sectors of society, especially in the monopoly of state-owned enterprises is more so. E \& D 
Institute is a comprehensive scientific research unit affiliated to Petro China Changqing Oilfield Company. Over the past 40 years, with the joint efforts of several generations of scientific and technical personnel, the Exploration and Development Research Institute has been exploring and developing low permeability oilfields in Ordos Basin. Changqing gas field has made outstanding contributions. However, in recent years, with the global economic downturn brought about by the decline in resource prices become an inevitable trend, the overall quality of the staff of the Institute can not keep up with the speed of oil field development, brain drain problem is very prominent. In the current economic situation is not optimistic, limited funds and not everyone's ultimate goal of the pursuit of money, making the re-design of the compensation must be faced with the Institute of strategic issues.

\section{The analysis of the status quo of Institute remuneration system}

\subsection{Analysis on the standing inventory of human resources in the institute}

Research Institute of the existing workforce, a total of national, provincial experts more than 10 people, including the age of 45 years of age there are 3 people. Enjoy the government special paste experts more than 20 people, including the age of 45 years of age 3 . The youngest expert is only 37 years old. Doctoral tutor 2 , master tutor more than 30 . These results in oil exploration and development has been a better application, and some into real productive forces, and achieved good social and economic benefits. However, with the energy and economic situation in recent years decline, the rate of brain drain increased significantly, especially in the senior titles of brain drain is particularly evident since 2010 , senior titles, the introduction of the cumulative number of 48 people, the loss of 57 people.

\subsection{The deficiencies of the existing human resources in institute}

Science and technology personnel education as a whole is not high. Research Institute is now more than post-graduate senior titles of scientific research staff less than $10 \%$ of all employees, some did not even reach the standard academic qualifications, the overall education was significantly lower than the industry average.

Scientific backbone loss is serious. From the past five years, the flow of personnel, the introduction of highly educated personnel decreased year by year, the loss trend is obvious. Worse still, during the 15th and 11th Five-Year Plan, the high-level professional and technical backbone introduced by the policy of western development has basically left all the staff in recent years. The loss of such talents can not be compensated through the introduction of doctorate or post-doctoral. 
The overall quality of newly introduced talents is declining. With the continued expansion of college enrollment, as well as the general trend of talent market, the overall quality of graduates is not high, even if high-quality, but also because of the larger employment options, outstanding graduates keen on large cities and coastal cities, only the whole Poor quality of the graduates to choose the western city.

The lack of internal competition incentive mechanism and constraint elimination mechanism makes the potential of scientific research personnel not fully exerted. Too many positive incentives to reinforce the role of obvious, but because of the lack of internal constraints, making the mixed day, unimpressed people have not been cleared in time, the staff enthusiasm and initiative to adversely affect.

\subsection{The salary levels in Institute}

During the 11th Five-Year Plan period, the global energy prices showed a general trend of rising steadily. The state supported the energy and chemical industries with a large amount of state key tasks undertaken by the Institute. With several state wage adjustments to public institutions, The income of staff and workers increased by a large margin, with an average annual growth rate of over $30 \%$. At the same time, various forms, explicit or implicit benefits, bonuses also make other units envy. Into the second five, with the monopoly of the people on the high salary, high welfare of the strong condemnation, the state began to control the monopoly of enterprise employees compensation, employee compensation is basically no major changes related to invisible benefits basically disappeared.

\subsection{The problems in existing pay system}

The total wage is low. With the situation of most state-owned enterprises is similar to the treatment of technical personnel and private enterprises compared to the gap between the current technical backbone of the main loss of private enterprises, accounting for more than $50 \%$ of the turnover of workers.

As the impact of scientific and technological achievements on enterprise efficiency needs to go through a long time, or there is a certain lag effect, making the technical backbone of the material incentives and contributions are not linked, thus affecting the stability of the technical backbone and work enthusiasm.

At present technical staff performance appraisal is reflected in the difficult to quantify the work attitude, spirit of cooperation, mutual help spirit, and many results depend on the human scoring queuing, it is difficult to scientific and objective evaluation of technical personnel contribution to the enterprise, and the inherent China 's human world, so that everyone' s results or less, this assessment is not conducive to make outstanding contributions to the staff get higher returns, nor to the poor performance of the corresponding penalties.

The backbone of the technical development needs of self-consideration. The current pay system rarely take into account the technical backbone such as further study, study abroad, exchange learning to enhance their own needs, even if these opportunities are often leading welfare, and the real struggle in the front line of 
scientific research is difficult to enjoy the backbone To this, this will affect the backbone of science and technology and the enthusiasm of the future work.

\section{The experience and inspiration of pay reform in domestic and foreign enterprises}

\subsection{Famous domestic large-scale enterprise incentive experience}

Haier's strategic compensation incentive system, Huawei's leading compensation strategy, FAW Great Chai's award-winning young scientific and technological personnel incentive system, Lenovo's employee dividend system in the pay incentive has made fruitful reforms worthy of other domestic enterprises learn and learn. To sum up, these companies in the pay attempt and effectiveness, there is worth learning from the common experience, including the continued increase in core staff salaries, through the incentive to retain the core employees equity, attention to employee motivation, emphasizing the fairness of pay without forgetting Competitiveness, attention to staff capacity for sustained growth has become the mainstream trend.

\subsection{Famous foreign large-scale enterprise salary incentive experience}

Incentives for executives and core technology talents in foreign countries can be summarized as American model, German model, Japanese model, etc., which can be distinguished mainly from the four aspects of total compensation, compensation structure, restraint mechanism,

\subsection{Inspiration}

Salary incentive system with a strong national characteristics, and their specific cultural atmosphere and the macro environment is closely related. The United States model of individualism, advocating freedom, the Japanese model and the German model in the culture more emphasis on teamwork, collective consciousness. Therefore, China's pay incentives must take into account the characteristics of these national conditions, taking into account the company's equity and capital markets, managers and other market factors, can not blindly copy.

Enterprises in the use of material incentives at the same time, can not ignore the importance of spiritual motivation, we should try to use "feelings keep people." Compared with Anglo-American, Japanese companies in the spirit of incentives have a clear advantage.

Improve the corporate governance institutions, strengthen the restraint mechanism. Perfect the corporate governance structure of the Company, strengthen the role of the shareholders' meeting, the board of directors and the board of supervisors, so as to strengthen the internal restraint mechanism, avoid the function dislocation and the restraint mechanism. 


\section{The redesign of the pay system}

Currently in the state organs and institutions, wages are divided into basic wages, job salaries, seniority wages, reward wages in four parts. Therefore, according to the management of the Institute of the status quo, at the same time learn from well-known large-scale corporate compensation system, the Institute of technical personnel compensation system set by the basic wage, technical grade wage component of the fixed salary and performance pay, project bonuses, The technology component of the active share of the equity.

\section{The supporting measures of scientific technological personnel compensation system in institute}

\subsection{Establish and improve the performance appraisal index system}

The role of the system is to avoid the implementation process of human feelings, to ensure that enterprises regulate the exercise and exercise of power, improve management efficiency. This is also the starting point for the establishment of performance appraisal system. Performance evaluation is to achieve the purpose of production and operation, the use of specific standards and indicators, the use of scientific methods, the work of employees in the past acts and to obtain the performance of work to assess. It can be said that the performance assessment is to use economic means to continuously strengthen the implementation of the positive objectives of the enterprise to achieve positive behaviour, to reduce the adverse objectives of the enterprise is not conducive to the behaviour of mining problems and stimulate staff potential and supervise the rapid growth of employees, Long - term development strategy.

\subsection{Expand the scope of non-material incentives}

Stiglitz once pointed out: Sometimes, non-economic incentives are very powerful, so that it seems to fundamentally replace the economic incentives. Because people's needs are diverse and hierarchical, incentives are demand-based, and the variety of needs naturally leads to diversity in the form of incentives. Because there are a large number of non-material needs of employees, which inevitably require the implementation of a large number of non-material incentives to produce effective incentive effect. Practice shows that the incentive effect of material incentives is the result of employee incentive and incentive-dependent. Flexible non-material incentives not only allow technicians to feel the Institute's long-term plans and care, and allows technical staff feel the cohesion of the Institute, thereby enhancing the satisfaction of technical staff to ease the technical staff occupational stress, to achieve more than pure substances Incentives more effective efficacy. By developing non-material incentives related to employee survival, employee relationships, and employee development needs, it will increase the attractiveness of the organization to its employees. 


\subsection{Establish the remuneration and communication channels}

In the salary management, there is a very important principle: pay is communication, if the technical staff does not know why the money, then the Institute even if the capital increase is also the technical staff will not play a stimulating effect. Therefore, it is essential that the Institute conducts effective communication when it develops and implements a new remuneration package. Institute of technical personnel of the Institute of remuneration policy and pay system know very little, only know how much monthly salaries, but never know why the money and why the collar of this number. Managers mistakenly believe that the remuneration management work is only the Institute of Personnel Department of things, and ordinary technical personnel has nothing to do, and even that the technical staff of the pay system more understanding, the more problems and troubles, so the technical staff should be unconditional accept. In this case, the Institute must abandon the traditional practice of closing salary information, investing some time and effort in the pay communication.

\subsection{Improve the career planning and design}

As a knowledge-based talent, technical personnel have a strong demand for personal career development, in order to allow technical staff to long-term stability in the Institute of active work for the technical staff of career management is a very important long-term incentives. The Institute of the technical staff of the current career management policy is mainly reflected in the promotion of technical cadres, but this promotion is often due to limited management positions are difficult to meet the outstanding technical staff promotion opportunities for major flaws, but not every technical personnel Are longing for "promotion", even if the "promotion" needs, whether the real "official" is not necessarily. In order to solve these problems, you can set the management approach and technical approach two career development direction to meet the different needs of technical staff.

\section{References}

[1] Chen Qingtai, Wu Jinglian, Introduction to Corporate Compensation System, China Financial and Economic Publishing House, pp.68-70, 2001

[2] Chen Xiaojun, listed companies information technology executives salary incentive research, Xinjiang University of Finance and Economics, 8 (5), pp.8791, 2007

[3] Cai Qian, Western incentive theory in the design of compensation, Entrepreneurs world, 12(10), pp. 18- 20, 2007

[4] Ran Bin, Wang Qing, Cai Wei, compensation program design and operation, China Economic Publishing House, pp.58- 61, 2003

[5] Liu Xianghong, GE Zhongfeng, Research on Flexible Incentive Model of Knowledge Worker, Technoeconomics \& Management Research, 8(4), pp.85-87, 2014 